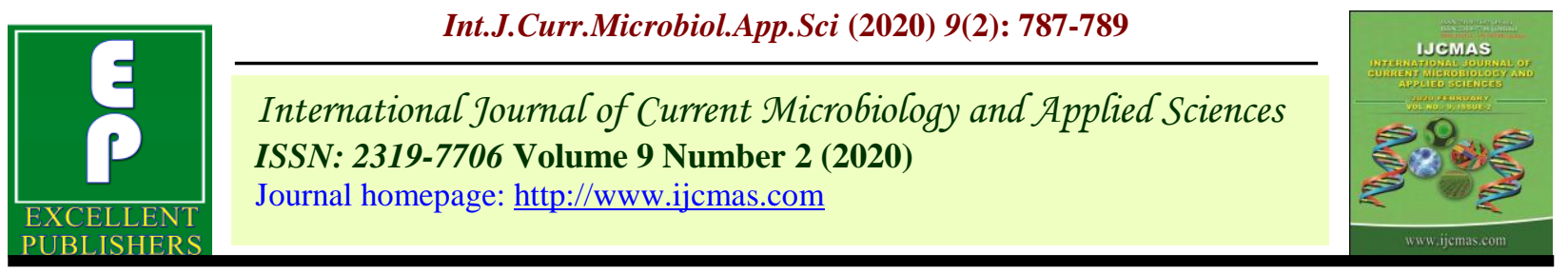

Case Study

https://doi.org/10.20546/ijcmas.2020.902.095

\title{
Surgical Management of Teat Fistula in Sirohi Goat- A Case Report
}

\author{
Mithilesh Kumar ${ }^{1 *}$, Imran Ali ${ }^{2}$ and Vishnu Prabhakar ${ }^{1}$ \\ ${ }^{1}$ Department of Veterinary Surgery and Radiology, ${ }^{2}$ Department of Veterinary Pathology, \\ Veterinary Surgery \& Radiology, BVC, Patna, India \\ *Corresponding author
}

\begin{tabular}{|l|}
\hline Ke y w o r d s \\
Goat, Xylocaine \\
2\%, Vicryl, \\
Adhesive tape, \\
Adhesive tape, \\
Infant feeding tube \\
\hline Article Info \\
\hline Accepted: \\
08 January 2020 \\
Available Online: \\
10 February 2020 \\
\hline
\end{tabular}

A B S T R A C T

A 2-year-old goat was presented to TVCC with history of leaking of milk through teared teat. On examination showed that teat was ruptured longitudinally about $2 \mathrm{~cm}$ in length. Milk was coming out through the injured area. Sedation of goat done under the Xylazine and caudal epidural anaesthesia for suturing of the teat with the help of chromic catgut no. 1 in under lying layer and superficial layer with the help of silk thread. The goat went to towards fencing area and suddenly teat was ruptured with pointed wire the wound was prepared aseptically for repair of teat. Teat was sutured with simple continuous in two layers in muscular area and interrupted suture in skin. Infant feeding tube no. 10 was inserted under the teat canal attached teat with leucoplast for 30 days. Milking was done through the infant feeding tube. Teat was remained complete rest for one month. Postoperatively the animal was maintained with antibiotics and antiinflammatory drugs.

\section{Introduction}

Teat fistula is opening of teat from teat cistern to outer surface leading to leaking of milk spontaneously from fistula observed when the teat is milked. Teat fistula is not common in goat. Glandular tissue is not associated with fistulas. The case treated urgently otherwise the lesion progress towards mastitis (Kumar 2000). Treat the animal earlier to prevent milk loss and to maintain better udder health. On physical examination body temp was normal and milk was also normal means free from systemic and local infection of teat. Teat was observed soft on palpation. Goat are important part of livestock for meat and milk purpose and has low productivity and high economic losses recorded by various surgical affections (Zabady et al., 2004, Abu Seida and Ahmed, 2007). Physical examination body temp., pulse rate and respiration rate were normal. Treatment of teat problems in many countries may be uneconomic lead to loss in milk yield, loss in antibiotic treated 
milk, Possible loss of quarter if dry off therefore better knowledge teat and udder for surgical affection needed (Schukken et al., 1992). Early diagnosis and treatment of teat and udder is very crucial for maintenance of health and milk production.

\section{Case history and treatment}

A goat suffering from teat injury reported at university veterinary hospital. Blood was coming drop by drop through teat. Animal was showing pain sensation by bleating. Injury was due to fencing wire. On physical examination body temperature, respiration and pulse rate was within physiological limit. Blood clotted teat was washed with normal saline. On palpation showed few drops of blood coming through injury teared area. Teat fistula longitudinally in the mid region was examined. Teat fistula was also reported by Kashyap et al., 2017. The other teat was found normal.

Preparation for surgery of teat fistula planned immediately to repair the fistula and prevent further infection. The case was desensitized with caudal epidural anaesthesia xylocaine $2 \%$ was given $2 \mathrm{ml} / 10 \mathrm{~kg}$ in the lumbosacral region

A $2 \mathrm{~mm}$ sterile Steinmann pin inserted inside

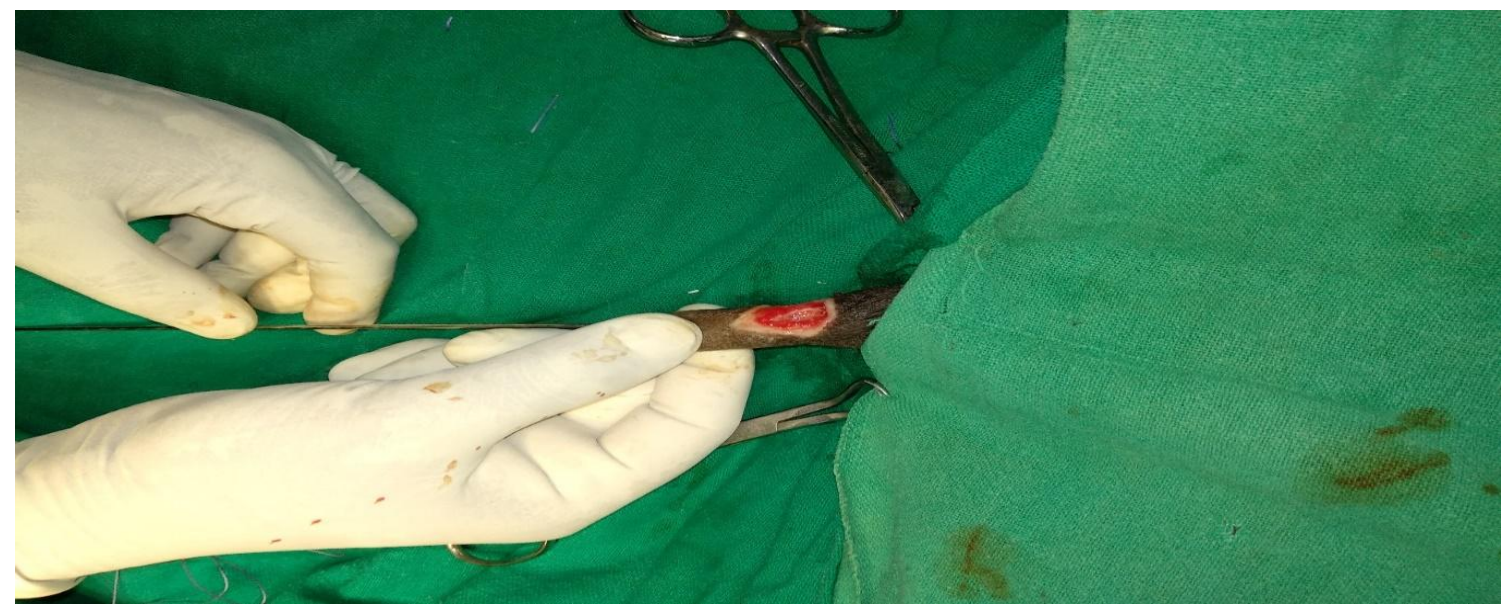

Fig.1 Insertion of Steinmann pin no. 2 inside teat canal for potency before suturing

the teat after aseptic preparation (Fig. 1). Suturing of teat in one layer in mucosa and submucosa and next other layer muscle with vicryl no. 1-0 in continuous pattern to seal the gap. Skin sutured with silk thread by mattress pattern.

An infant feeding tube no. 8 inserted inside the teat canal upto gland cistern for milking without using hand. Wound remained rest for healing of the tissue. Size of tube is slightly greater than teat was inserted inside upto gland cistern after cutting the length required (Fig. 2) Knob side tube was used for teat after cutting the length. Tube fixed with teat by adhesive tape for 15 days (Fig. 2). Antibiotic Amoxicillin and sulbactam $5 \mathrm{mg} / \mathrm{kg}$ body wt. for 7 days and Meloxicam $0.2 \mathrm{mg} / \mathrm{kg}$ body wt. for 3 days was used in postoperatively. Knob of the tube kept open for 10 days (Fig. 3). Load of milk could not be leaking through newly sutured area. During sitting position knob of the tube was closed to prevent infection from the soil. Last 5 days knob was closed however milk was not dribbling through the newly sutured area. It means healing was completed. Gentamicin $0.2 \mathrm{ml}$ diluted with NS $3 \mathrm{ml}$ infused into teat evening and morning at the milking time. Sutured removed after 15 days. Animal recovered uneventfully. Milking done normally. 


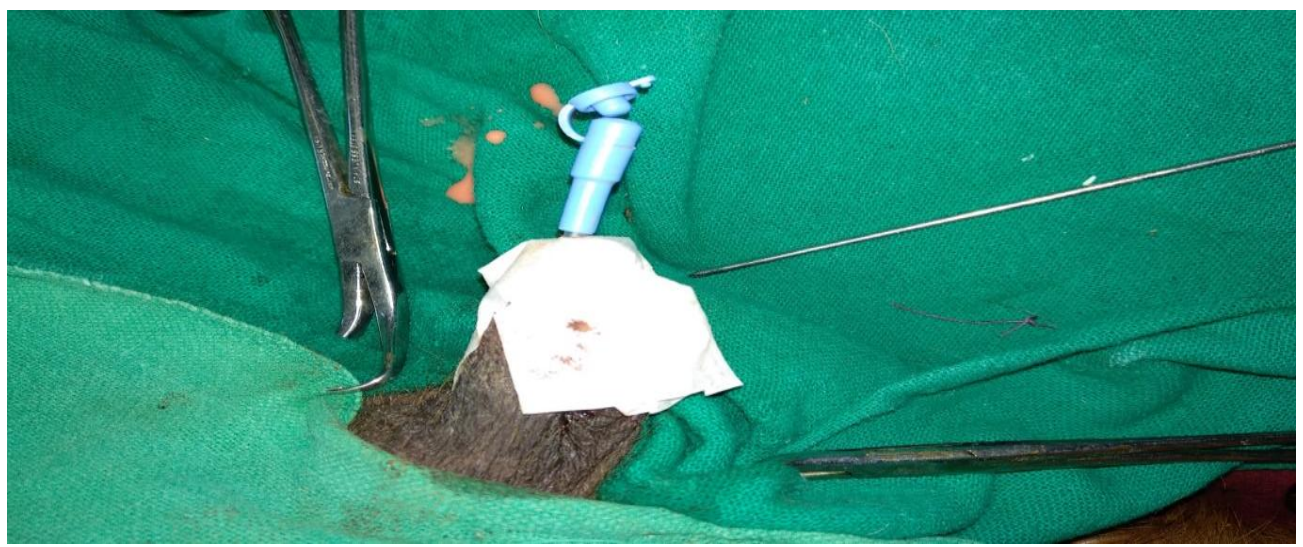

Fig. 2 Introduction of Infant feeding tube inside the teat canal and attached by adhesive tape

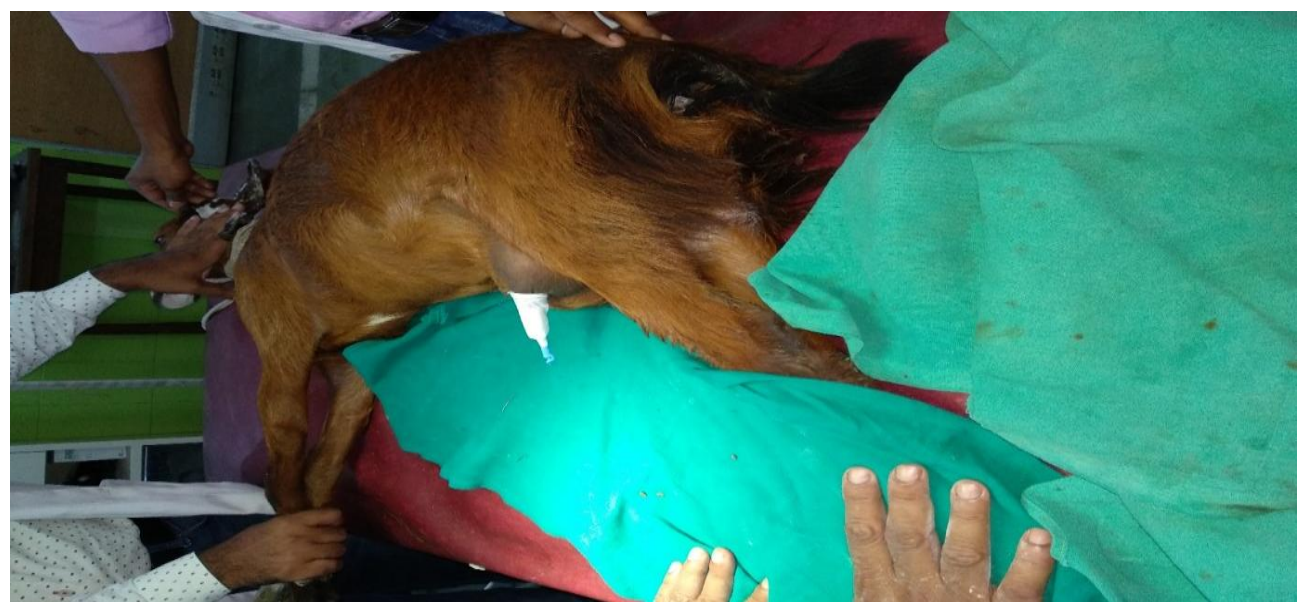

Fig.3 Milking by opening the knob of tube

\section{References}

Abu-Seida AM, Ahmed KA (2007) External neoplasms in goats: A clinicopathological study on five types. Vet Med J., 55:33-44.

Kashyap, D. K., Giri, D. V. and Dewangan, G. (2017). Teat Fistula in Jamunapari Goat-A Case Report. Explor. Anim Med Res, Vol. 7, Issue - 2, 2017, p. 230-231.
Kumar, A (2000) Surgical management of teat laceration or fistula. In: Veterinary Surgical techniques. Vikas Publishing House Pvt. Ltd. New Delhi. Pp. 223226.

Schukken, Y. H., Lesile, K. E., Weeersink, A. J. and Martin, S.W. (1992). Ontario bulk milk somatic cell count reduction program. J. Dairy Sci. 75, 3352-3358.

\section{How to cite this article:}

Mithilesh Kumar, Imran Ali and Vishnu Prabhakar. 2020. Surgical Management of Teat Fistula in Sirohi Goat- A Case Report. Int.J.Curr.Microbiol.App.Sci. 9(02): 787-789. doi: https://doi.org/10.20546/ijcmas.2020.902.095 